\title{
Uncertainty in photo-interpreted forest inventory variables and effects on estimates of error in Canada's National Forest Inventory
}

\author{
by Steen Magnussen ${ }^{1,2}$ and Glenda Russo ${ }^{1}$
}

\begin{abstract}
Canada's National Forest Inventory (NFI) relies on photo-interpreted forest resource data provided by provincial and territorial agencies. NFI data are collected at regular intervals in time from a nominal $20 \times 20 \mathrm{~km}$ network of $2 \times 2 \mathrm{~km}$ photoplots. Attribute-specific NFI estimates of precision include contributions from sampling errors and uncertainty in the source data. We assessed this uncertainty in NFI photo-interpreted forest attribute data from New Brunswick and Nova Scotia. Attributes examined were: cover type, age, maturity (class), crown closure, height, volume, and area associated with an attribute. Monte-Carlo simulations, with measurement errors superimposed on NFI data assumed to be error-free, showed that estimates of precision were inflated by an average of $7 \%$ (range $0 \%-36 \%$ ) due to the uncertainty in the source data. Species misclassification and age determination were the largest sources of uncertainty.
\end{abstract}

Key words: national inventory, aerial photographs, sampling error, precision, simulation, measurement error, error budget

\section{RÉSUMÉ}

L'Inventaire forestier national du Canada (IFN) repose sur les données de photo-interprétation des ressources forestières fournies par les organismes provinciaux et territoriaux. Les données de l'IFN sont recueillies à des intervalles réguliers selon un réseau de base de $20 \mathrm{X} 20 \mathrm{~km}$ composé de parcelles-photos de $2 \times 2 \mathrm{~km}$. Les estimations de la précision de l'IFN établi selon des attributs spécifiques tiennent compte des erreurs déchantillonnage et des sources de confusion affectant les données de base. Nous avons évalué cette confusion entourant les données photo-interprétées des attributs forestiers dans le cas du Nouveau-Brunswick et de la Nouvelle-Écosse. Les attributs retenus étaient : le type de peuplement, lâge, la classe de maturité, la fermeture du couvert, la hauteur, le volume et la superficie associée à l'attribut. Des simulations de type Monte-Carlo, avec les erreurs de mesurage superposées sur les données de l'IFN considérées comme ne contenant pas d’erreur, ont indiqué que les estimés de la précision étaient exagérés en moyenne de $7 \%$ (variation de $0 \%$ à $36 \%$ ) à cause des sources de confusion comprises dans les données de base. La mauvaise classification des espèces et la détermination de lâge constituaient les plus importantes sources de confusion.

Mots clés : inventaire national, photographies aériennes, erreur déchantillonnage, précision, simulation, erreur de mesurage, comptabilité de l'erreur

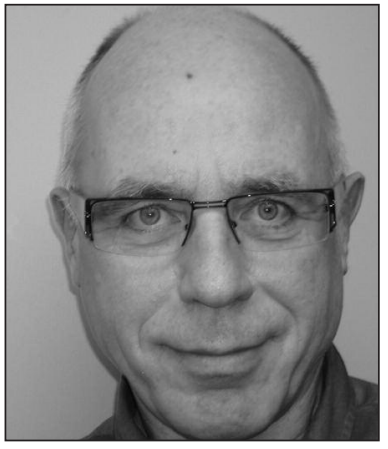

Steen Magnussen

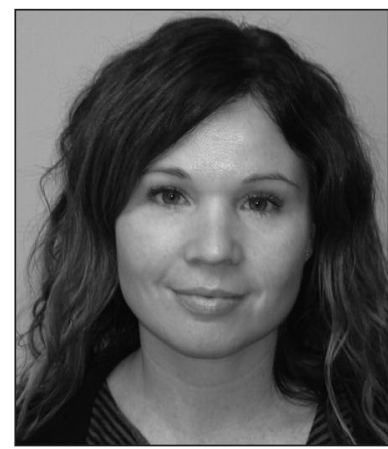

Glenda Russo

\section{Introduction}

Interpretation of aerial photographs for the extraction of forest and landscape attributes remains a cost-effective option for large-scale regional natural resource inventories (Eid and Næsset 1998, Cots-Folch et al. 2007, Magnusson et al. 2007,

Morgan et al. 2010, Ståhl et al. 2011). Quantitative and qualitative attribute values extracted from an image, whether through automated, semi-automated or manual processes, will never correspond exactly to benchmarked attribute values obtained through laborious and time-consuming field procedures. Thus, data extracted from an image contain errors to be recognized in further processing and use of the data (Cox 1976; Duvemo and Lämås 2006; Särndal et al. 1992: ch. 16; Haara and Leskinen 2009).

In forest inventories the prevailing use of aerial photographs is for stratifying the land into forest stands (polygons) based on attributes such as species composition, height, and canopy closure, as well as considerations regarding land use, wildlife, plant life, protection, and access (Shedha and Natarajan 1978, Gillis and Leckie 1993, Spencer 1998, Kohl and Keller 1999). A suite of stand-level attributes is then interpreted, identified, or predicted from models. Various levels of uncertainty are associated with extracted attribute values. The level of uncertainty is influenced by many factors, for example, interpreter skills, image quality and resolu-

\footnotetext{
${ }^{1}$ Natural Resources Canada, Canadian Forest Service, Pacific Forestry Centre, 506 West Burnside Road, Victoria, BC V8Z 1M5

${ }^{2}$ Corresponding author. E-mail: Steen.Magnussen@nrcan.gc.ca
} 
tion, employed soft-copy technology, topography, complexity of the land cover, season of image capture, inventory definitions, minimum mapping units, and required details in extracted attributes (Hall and Fent 1991, 1996; Næsset 1991a; Ståhl 1992; Leckie and Gillis 1995; Strand et al. 2002). A comprehensive quantification - or rather estimation —of this uncertainty is a complex challenge, and is rarely done due to the considerable expense incurred by such an undertaking (Ståhl 1992). Furthermore, each inventory will typically have its own distinct profile of uncertainty. Uncertainty in interpreted attributes of a single forest stand can be expected to be relatively large (e.g., 20\%).

Forest resource data derived from aerial photographs are also used in sample-based forest resource surveys (Spencer and Czaplewski 1997, Frayer and Furnival 1999, Gillis et al. 2005). In these cases, a direct application of a design-based estimator of sampling error will not reflect that the data include errors of measurement (Loetsch et al. 1973; Särndal et al. 1992: ch. 16; Ståhl 1992; Næsset 1995). When attribute extraction has been done by skilled interpreters subject to ongoing quality controls (audits), or by locally validated semior fully-automated procedures, it is reasonable to assume that the errors in interpreted (extracted) data will average to zero across a large number of sampling units. In large sample applications it can therefore be assumed that estimates of totals and means are unbiased.

A direct application of a design-based estimator of sampling error to survey data with measurement errors yields an estimate of precision that includes a contribution from sampling variance as well as measurement errors (Fuller 1987, Carroll et al. 1995, Lesser and Kalsbeek 1999). In other words, the apparent sampling error is inflated by the noise in the data. In hypothesis testing, the contribution of measurement errors to the estimate of precision leads to an inflated Type II error rate (failure to reject a false null hypothesis) (Fuller 1987).

Canada has established a national forest inventory (NFI) composed of national network of plots on a $20 \mathrm{~km} \times 20 \mathrm{~km}$ grid covering the national surface area, with the exception of the permanently non-vegetated parts in the far north (Gillis et al. 2005). Each plot measures $2 \mathrm{~km} \times 2 \mathrm{~km}$. Combined, they cover approximately $1 \%$ of Canada's landmass south of the Arctic. Photo-interpreted data, for plots located in the parts of Canada covered by provincial and territorial inventories, are provided by provincial and territorial agencies. Soft-copy technology is increasingly employed in this endeavor. The original image resolution is typically in the range from 1:10 000 to 1:20 000 (Gillis and Leckie 1993). In areas not covered by provincial or territorial inventories, the data are generated from satellite-derived information. To distinguish these plots from traditional inventory sample plots they are collectively referred to as photo-plots. Data for national and international reporting-primarily on the extent of land use and land cover, forest characteristics, and tree-size-related attributes-are obtained at regular intervals in time. The ensemble of photo-plots is considered as a probability sample, and adopted estimators of totals (means) and sampling errors are those applicable to a single-stage cluster design (Levy and Lemeshow 1991). Thus, the uncertainty in the source data is not recognized explicitly. Reported estimates of apparent sampling error are actually estimates of precision containing contributions from both sampling errors and measurement errors.

This study attempts to quantify how uncertainty in the NFI source data impacts on estimates of precision. Our approach employs simulated interpretation errors with replicated analysis of perturbed and non-perturbed NFI source data (assumed to be error-free). The perturbations are designed to mirror actual uncertainty in photo-interpreted data acquired from aerial photographs in a scales of 1:12 500 and 1:15 000. While results are limited to the provinces of New Brunswick (NB) and Nova Scotia (NS), the models derived for the measurement errors may find wider application.

\section{Materials and Methods}

We obtained estimates of uncertainty in photo-interpreted, stand-level forest inventory attribute values from New Brunswick and Nova Scotia through a combination of on-site interviews with experienced and skilled interpreters in March of 2011, and a review of pertinent literature (Næsset 1991b, 1992, 1997, 1998, 1999; Magnussen 1996, 1997a,b, 1998; Hall and Fent 1996; Ståhl 1992; Congalton and Mead 1999; Strand et al. 2002).

For a quantitative trait, uncertainty is, in this study, expressed as a percent of the true but unknown value. For a qualitative trait, uncertainty is expressed as the chance (probability) of a correct classification (Congalton 2001). In our analyses, we assume a zero-correlation amongst interpretation errors in different attribute values. Consequently, results should be viewed as capturing the marginal effect of uncertainty in each reported attribute (Fuller and Battese 1974, Fuller 1987, Mäkinen et al. 2010). Given the correlation of many forest attributes, one should expect errors to be correlated for some combinations of attributes (Mäkinen et al. 2010). However, one should also expect significant interpreter effects in these correlations. Without data to substantiate the correlation structure, we adopted the notion of independence. It is not possible to gauge the consequences of this simplification since some correlations will be positive, and others negative.

We also assumed that the level of uncertainty in each examined inventory attribute is the same in the two provinces. Although differences do exist in interpretation guidelines, forest structures, and imagery, they are minor and were considered unimportant for this study. Nevertheless, our simplifications mean that results should be interpreted as first-order approximations.

Photo-plot data used in the NFI consist of a large suite of interpreted (or modeled) forest attribute values (over 50) recorded for each delineated sub-plot area. As such, the photo-plot can be interpreted as a cluster with a variable number of unequal-sized sub-plot areas, each with a detailed list of attribute values. Here we limit the study to only eight of the most important attributes: 1) cover type (hardwoods, softwoods, mixed-woods), 2) leading species composition, 3) maturity class $(\mathrm{MC})$ : regeneration $(\mathrm{R})$, sapling $(\mathrm{S})$, young $(\mathrm{Y})$, immature (I), mature (M), and over-mature $(\mathrm{O}), 4)$ age (years, of leading species), 5) stand height (m), 6) canopy closure (proportion of land-covered by a vertical projection of 
tree crowns on a horizontal projection of the polygon), 7) stem volume $\left(\mathrm{m}^{3} \mathrm{ha}^{-1}\right)$, and 8$)$ area (ha).

Our approach to quantify the impact of uncertainty in photo-interpreted data on NFI estimates of precision was through use of models guided by expert opinions, and Monte Carlo simulation with data from the national grid of 352 photo-plots distributed as 194 for NB and 158 for NS. The original photo-plot data were, for the purpose of this study only, considered to be without errors, i.e., the recorded values equal the actual (true) values. Each recorded attribute value $(X)$ for a sub-plot area in a photo-plot were transformed to a new (random) attribute value $X^{\star}$ according to a model of uncertainty in the interpreted attribute. For a quantitative attribute like area, age, height, volume, or canopy closure, $X^{\star}$ is equal to the original $X$ plus an error term drawn at random from an assumed attribute-specific distribution for the error process. Error distributions typically depend on factors like species, species group, and maturity. For a qualitative attribute (species, maturity, cover type), the transformation from $X$ to $X^{\star}$ was done by a random draw from a discrete probability distribution for the possible states of $X^{\star}$ conditional on $X$ (Congalton 2001). Without quantitative data to guide the choice of an error distribution, we opted for symmetric distributions on a domain assumed to capture the range of actual errors.

For each quantitative attribute and photo-plot, we computed a per-unit-area value as a weighted mean; call it $X_{i}^{\star}, i=1, \ldots, 352$. Weights were the sub-plot areas associated with the attribute in question. We then computed the mean of $X^{\star}$ across the 352 photo-plots $\left(\bar{X}^{\star}\right)$, and obtained an estimate of precision (viz. presumed sampling error) $\hat{s e}\left(\bar{X}^{\star}\right)$ as the square root of the among-plot variance of $X^{\star}{ }_{i}$ divided by the sample size (352) (Cochran 1977). For each qualitative attrib- ute $\left(X^{\star}\right)$ we report on the average area (or area proportion) with this attribute in a photo-plot. Again, the square root of the among-plot variance of these areas divided by the sample size served as our estimate of precision.

The above process of transforming $X$ to $X^{\star}$ and computing sample averages and precision was done on the combined NB and NS data and repeated 600 times (Monte Carlo replications) in order to obtain not only a precise estimate of the average precision of $\bar{X}^{\star}$ but also a robust estimate of the among-replication variance of $\bar{X}^{\star}$, which we then incorporated-by standard procedures-into a final estimate of $\hat{s e}\left(\bar{X}^{\star}\right)$ (Rubin 1987).

Estimates of precision of $\bar{X}^{\star}$ were compared to corresponding estimates for the assumed actual (recorded) value of $X$ (computed as above, but with $X$ replaced by $X^{\star}$ ). To remove scale effects, we report on relative precision, i.e., the precision in percent of $\bar{X}$.

\section{Uncertainty in land cover classification}

A NFI photo-plot represents a $2 \mathrm{~km} \times 2 \mathrm{~km}$ map delineated by an interpreter to a set of sub-plot areas according to a suite of land use, land cover, and forest attributes. A sub-plot area is classified into one of 14 land cover classes (Table 1). Photointerpretation incurs the risk of an incorrect classification as a result of errors in line placement and/or label assignment. The risk varies greatly among cover classes, from approximately $0 \%$ (water) to $25 \%$ for classes TB (treed, broadleaves), TC (treed, coniferous), and TM (treed, mixture of broadleaves and coniferous). Delineation of each sub-plot area is also subject to uncertainty (see Uncertainty in sub-plot areas).

The high chance of an incorrect TB, TC, or TM classification does not reflect a problem with interpretation per se, but

Table 1. Uncertainty in interpretation of land cover. Table entries are the conditional probability that the actual land cover is $\mathrm{X}$ when the interpreted type is $\mathrm{X}^{*}$. Land cover legend: $\mathrm{BM}=$ Moss, $\mathrm{BL}=$ Bryoid lichens, $\mathrm{BY}=\mathrm{Bryoids}$, EL = exposed land, $\mathrm{HE}=$ herbs, $\mathrm{HF}=$ forbs, $\mathrm{HG}$ = gaminoids, $\mathrm{RO}=$ Rock/rubble, $\mathrm{SL}=$ shrub low ST = shrub tall, $\mathrm{TB}=$ treed broadleaves (hardwood content $\geq 75 \%$ ), TC = treed coniferous (softwood content $\geq 75 \%$ ), TM = treed mixed-wood (softwood and hardwood content is $\geq 25 \%$, WA = water.

\begin{tabular}{lccccccccccccccc}
\hline & BM & BL & BY & EL & HE & HF & HG & RO & SL & ST & TB & TC & TM & WA \\
\hline $\mathrm{BM}^{*}$ & 0.97 & 0.01 & 0.01 & 0 & 0.01 & 0 & 0 & 0 & 0 & 0 & 0 & 0 & 0 & 0 \\
$\mathrm{BL}^{*}$ & 0.01 & 0.97 & 0.01 & 0 & 0.01 & 0 & 0 & 0 & 0 & 0 & 0 & 0 & 0 & 0 \\
$\mathrm{BY}^{*}$ & 0.01 & 0.01 & 0.97 & 0 & 0.01 & 0 & 0 & 0 & 0 & 0 & 0 & 0 & 0 & 0 \\
$\mathrm{EL}^{*}$ & 0 & 0 & 0 & 0.95 & 0 & 0 & 0 & 0.05 & 0 & 0 & 0 & 0 & 0 & 0 \\
$\mathrm{HE}^{*}$ & 0 & 0 & 0.01 & 0 & 0.97 & 0.01 & 0.01 & 0 & 0 & 0 & 0 & 0 & 0 & 0 \\
$\mathrm{HF}^{*}$ & 0 & 0 & 0.01 & 0 & 0.01 & 0.97 & 0.01 & 0 & 0 & 0 & 0 & 0 & 0 & 0 \\
$\mathrm{HG}^{*}$ & 0 & 0 & 0.01 & 0 & 0.01 & 0.01 & 0.97 & 0 & 0 & 0 & 0 & 0 & 0 & 0 \\
$\mathrm{RO}^{*}$ & 0 & 0 & 0 & 0.05 & 0 & 0 & 0 & 0.95 & 0 & 0 & 0 & 0 & 0 & 0 \\
$\mathrm{SL}^{*}$ & 0 & 0 & 0 & 0 & 0 & 0 & 0 & 0 & 0.95 & 0.05 & 0 & 0 & 0 & 0 \\
$\mathrm{ST}^{*}$ & 0 & 0 & 0 & 0 & 0 & 0 & 0 & 0 & 0.09 & 0.75 & 0.08 & 0 & 0.08 & 0 \\
$\mathrm{~TB}^{*}$ & 0 & 0 & 0 & 0 & 0 & 0 & 0 & 0 & 0 & 0 & 0.75 & 0 & 0.25 & 0 \\
$\mathrm{TC}^{*}$ & 0 & 0 & 0 & 0 & 0 & 0 & 0 & 0 & 0 & 0 & 0 & 0.75 & 0.25 & 0 \\
$\mathrm{TM}^{*}$ & 0 & 0 & 0 & 0 & 0 & 0 & 0 & 0 & 0 & 0 & 0.12 & 0.13 & 0.75 & 0 \\
$\mathrm{WA}^{*}$ & 0 & 0 & 0 & 0 & 0 & 0 & 0 & 0 & 0 & 0 & 0 & 0 \\
\hline
\end{tabular}


Table 2. Assumed probability (P) of a correct species (S) identification in the topmost canopy layer of a stand. Estimated abundance class of species in New Brunswick and Nova Scotia is indicated $(H=$ high, $A=$ average, $L=$ low, $R=$ very low). Species codes as per "NFI Photo-plot Data Dictionary for Remeasurement" Version 5.1.2 (2009) at https://nfi.nfis.org/photo_plot.php? lang=en.

\begin{tabular}{|c|c|c|c|c|c|c|c|}
\hline $\begin{array}{l}\text { Species } \\
(S)\end{array}$ & Abundance & $\begin{array}{c}\text { Probability } \\
\qquad S^{*}=S\end{array}$ & $\begin{array}{c}S \text { is most } \\
\text { often } \\
\text { confused with }\end{array}$ & $\begin{array}{c}\text { Species } \\
(S)\end{array}$ & Abundance & $\begin{array}{c}\text { Probability } \\
\qquad S^{*}=S\end{array}$ & $\begin{array}{c}S \text { is most } \\
\text { often } \\
\text { confused with }\end{array}$ \\
\hline ABIE_BAL & $\mathrm{H}$ & 0.90 & PICE_MAR & PICE_ABI & $\mathrm{R}$ & 0.85 & PICE_RUB \\
\hline ACER_PEN & $\mathrm{R}$ & 0.50 & ACER_SPI & PICE_GLA & $\mathrm{H}$ & 0.90 & ABIE_BAL \\
\hline ACER_RUB & $\mathrm{H}$ & 0.75 & ACER_SAH & PICE_MAR & $\mathrm{H}$ & 0.90 & ABIE_BAL \\
\hline ACER_SAH & $\mathrm{H}$ & 0.80 & ACER_RUB & PICE_RUB & $\mathrm{H}$ & 0.85 & PICE_MAR \\
\hline ACER_SPI & $\mathrm{R}$ & 0.50 & ACER_PEN & PICE_SPP & n.a. & 1.00 & PICE_SPP \\
\hline ACER_SPP & n.a. & 1.00 & ACER_SPP & PINŪBAAN & $\mathrm{A}$ & 0.85 & PICE_MAR \\
\hline ALNU_INC & A & 1.00 & ALNU_INC & PINU_RES & $\mathrm{R}$ & 0.90 & PINU_SPP \\
\hline BETU_ALL & A & 0.50 & BETU_POP & PINU_SPP & n.a. & 1.00 & PINU_SPP \\
\hline BETU_PAP & $\mathrm{H}$ & 0.50 & BETU_POP & PINU_STR & $\mathrm{A}$ & 0.95 & LARI_LAR \\
\hline BETU_POP & $\mathrm{R}$ & 0.50 & BETU_PAP & POPU_BAL & $\mathrm{R}$ & 0.95 & POPU_TRE \\
\hline BETU_SPP & n.a. & 1.00 & BETU_SPP & POPU_GRA & $\mathrm{R}$ & 0.50 & POPU_TRE \\
\hline CARP_CAR & $\mathrm{R}$ & 0.80 & ALNU_INC & POPU_SPP & A & 1.00 & POPU_SPP \\
\hline FAGU_GRA & $\mathrm{R}$ & 0.90 & TSUG_CAN & POPU_TRE & $\mathrm{H}$ & 0.75 & POP_GRA \\
\hline FRAX_AME & $\mathrm{R}$ & 0.70 & ACER_RUB & PRUN_PEN & $\mathrm{R}$ & 0.80 & SALI_SPP \\
\hline GENC_SPP & n.a. & 1.00 & GENC_SPP & QUER_RUB & $\mathrm{R}$ & 0.90 & POPŪ_GRA \\
\hline GENH_SPP & n.a. & 1.00 & GENH_SPP & SALI_SPP & n.a. & 0.80 & POPU_BAL \\
\hline LARI_LAR & A & 0.90 & PINU_GLA & SORB_AME & $\mathrm{R}$ & 0.80 & PRUN_PEN \\
\hline MALU_FUS & $\mathrm{R}$ & 0.80 & SORB_AME & THUJ_OCC & A & 0.80 & TSUG_CAN \\
\hline OSTR_VIR & $\mathrm{R}$ & 0.70 & CARP_CAR & TSUG_CAN & $\mathrm{R}$ & 0.80 & THUJ_OCC \\
\hline
\end{tabular}

rather the fact that most forest stands in NB and NS are mixtures of softwood and hardwood species. The seemingly low classification precision is therefore a consequence of difficulties in ascertaining species proportions as they are largely based on a judgment call. Also, the actual mixture of hardwoods and softwoods in many stands is close to the boundary between two classes. Even a relatively small error in species proportions may trigger a shift in its classification label assignment.

\section{Uncertainty in leading species}

The national photo-plot system allows for a maximum of 10 species in the visible topmost canopy layer in a sub-plot area, each accounting for a minimum of $10 \%$ by volume, basal area, stem count, or projected crown area. In the data from NB and NS the maximum number of recorded species in the topmost canopy layer was 8 , and the mean was 3.6. Many species are relatively easy to identify in an aerial image-with adequate resolution and image contrast-due to unique characteristics and known site requirements (Næsset 1992, O'Cuilinn 1994). Some species can be very difficult to identify beyond genus (e.g., poplars [Populus spp.], willows [Salix spp.], cherries [Prunus spp.]). In our Monte Carlo simulations we simplified the species confusion to species pairs consisting of: the actual species $(S)$, and the species $\left(S^{*}\right)$ most likely to be confused with the assumed species. The assumed probabilities of a correct species call $P\left(S^{*}=S\right)$ are listed in Table 2 for all encountered species (38). Accordingly, for a species called $S$ we drew a random number $u$ from a uniform distribution on the interval $[0,1]$ and if $u \leq P\left(S^{*}=S\right)$ the species was maintained as $S$; otherwise, it was changed to the species $S^{*}$ with which it was most likely confused (see Table 2 for details).
Table 3. Uncertainty in maturity class (MC) of leading species. Table entries are the conditional probability that the actual $M C$ is $X$ given the interpreted class is $X^{\star}$. MC legend: $R=$ Regeneration, $\mathbf{S}=$ sapling, $Y=$ young, $\mathrm{I}=$ Immature, $\mathrm{M}=$ Mature, $\mathbf{O}=$ Over-mature.

Actual class

\begin{tabular}{|c|c|c|c|c|c|c|}
\hline $\begin{array}{l}\text { Interpreted } \\
\text { class }\end{array}$ & d $\mathbf{R}$ & $S$ & $\mathbf{Y}$ & I & $\mathbf{M}$ & O \\
\hline $\mathrm{R}^{*}$ & 0.975 & 0.025 & 0.000 & 0 & 0 & 0 \\
\hline$S^{*}$ & 0.025 & 0.950 & 0.025 & 0 & 0 & 0 \\
\hline $\mathrm{Y}^{*}$ & 0 & 0.050 & 0.900 & 0.050 & 0 & 0 \\
\hline $\mathrm{I}^{*}$ & 0 & 0 & 0.070 & 0.860 & 0.070 & 0 \\
\hline $\mathrm{M}^{*}$ & 0 & 0 & 0 & 0.070 & 0.860 & 0.070 \\
\hline $\mathrm{O}^{*}$ & 0 & 0 & 0 & 0 & 0.200 & 0.800 \\
\hline
\end{tabular}

\section{Uncertainty in maturity class}

Sub-plot areas are classified to a maturity class based on the age $(s)$ of the leading species. Due to uncertainty in age assessment, a recorded maturity class is also subject to uncertainty. The uncertainty is quantified in Table 3 in the form of a "confusion" matrix (Magnussen 1997a). The simulation of maturity class used the conditional class membership probabilities in Table 3. For example, if the recorded maturity class was mature (M) there would be a $86 \%$ chance that the simulated call would also be $\mathrm{M}$, a $7 \%$ chance that the simulated call would be immature (I), and a $7 \%$ chance that it would be over-mature $(\mathrm{O})$. 


\section{Uncertainty in age of leading species}

In NB and NS the age of leading species in a sub-plot area is determined by $i$ ) models relating age to height, ii) management records, iii) updates to the age recorded in the previous inventory, and iv) information about local site productivity. As for other attributes, we consider a recorded age as the sum of an actual age plus an error term. For ages recorded in 10year class intervals, we used the class midpoint in our simulations. Based on our interviews and analyses of provincial sample plots, we adopted the following model that is dependent on maturity class (MC) and species group (SG):

$$
\begin{aligned}
& \text { [1] } T_{i j k}^{*}=T_{i j k} \times \varepsilon T_{i j k}, \varepsilon T_{i j k} \sim T D\left(1-2 \sigma_{v}(M C, S G) ;\right. \\
& \left.1+2 \sigma_{v}(M C, S G)\right)
\end{aligned}
$$

where $T_{i j k}$ is the recorded age for the $k$ th leading species in the $j$ th sub-plot area in the $i$ th photo-plot, and $\varepsilon T_{i j k}$ is a random multiplicative error term drawn from a symmetric triangular distribution (TD, Johnson et al. 1995: 297) on the interval [1 $\left.2 \sigma_{v}(M C, S G) ; 1+2 \sigma_{T}(M C, S G)\right]$. Values of the relative age error $\sigma_{v}$ by maturity class (MC) and species group (SG) are in Table 4. Our choice of distribution (TD) was guided by a desire to cap the relative errors to twice the typical error based on expert opinions (Table 4). Larger errors were deemed unlikely. Following the simulation of $T_{i j k}^{*}$, the final age assigned to the topmost canopy layer in a stand was a volumeweighted average of $T_{i j k}^{*}$. A photo-plot age $T_{i k}^{*}$ is then the areaweighted average for the $i$ th photo-plot.

Table 4. Relative uncertainty in age determination of leading species by maturity class (MC) and species group (SG). Uncertainty is expressed in percent of the age assigned to a leading species.

\begin{tabular}{lcccccc}
\hline & \multicolumn{5}{c}{ Maturity class } \\
\cline { 2 - 7 } $\begin{array}{l}\text { Species } \\
\text { group }\end{array}$ & $\mathbf{R}$ & $\mathbf{S}$ & Y & I & M & O \\
\hline Softwoods & 10 & 8 & 10 & 15 & 15 & 15 \\
Hardwoods & 20 & 10 & 15 & 20 & 20 & 20 \\
\hline
\end{tabular}

\section{Uncertainty in tree height of leading species}

Tree heights can be measured on digitized stereo-pairs of aerial photographs (e.g., Korpela 2004) provided one has a clear view of the terrain surface below the trees. Uncertainty in recorded tree heights is therefore dominated by measurement errors and interpreter skills. Here uncertainty in estimates of the average tree height $\left(H T_{i j k}\right)$ of dominant and codominant trees of the leading species in each sub-plot area was simulated by adding a normally distributed error $(\varepsilon H T)$ to a recorded tree height. The error term has a mean of zero and a standard deviation $\sigma_{\varepsilon H T}(M C, L A Y E R, T A X A)$ specific to maturity class (MC), vertical structure (LAYER), and species group (TAXA). See Table 5 for details. Following the simulation of $H T^{*}{ }_{i j k}$, the height assigned to the topmost canopy layer in a sub-plot area is a volume-weighted average of $H T^{\star}{ }_{i j k}$. A photo-plot height $H T^{*}$ ik then the areaweighted average for the $i$ th photo-plot.

\section{Uncertainty in crown closure}

Crown closure $(C L)$ is expressed as the proportion $(0 \leq C L \leq 1)$ of a sub-plot area covered by a vertical projection of the tree crowns onto this area (Avery and Burkhart 1983). Crown closure is typically given to the nearest $10 \%$. The interviewed photo interpreters suggested a typical uncertainty of approximately 0.06 , which, in our simulations, was implemented by assigning a closure $C L^{*}{ }_{i j}$ to the $j$ th sub-plot area in the $i$ th photo-plot by a random draw from a beta distribution, with a mean equal to the recorded value $C L_{i j}$ and a standard deviation of 0.06 . The beta distribution was chosen due to its ease of use with predetermined values for the mean and standard deviation. Crown closure in sub-plot areas with a $C L_{i j} \leq 0.10$ was not modified; we assumed these observations to be correct.

\section{Uncertainty in stem volume}

Stem volume $\left(V, \mathrm{~m}^{3} \mathrm{ha}^{-1}\right)$ is determined as the sum of leading species volume estimates. Only species with a crown cover of at least $10 \%$ contribute to the volume estimate. In the case of NB and NS, the volume estimates are provided through models (tariffs, look-up tables, equations) with entries by, for example, species, height, and age (Magnussen 1998). Uncertainty in volume estimates depends on the species group (softwoods, hardwoods) and on the regional abundance of the tree species. The uncertainty is lowest for common (familiar) species and highest for less common or rare species. Volume models are typically only available for the five to six most common species, and quality controls (field checks, audits) of volume estimates favour common stand types. We used an error simulation similar to that for age: we simulated the volume of species $k$ in the $j$ th sub-plot area and the $i$ th photoplot as

$$
\text { [2] } V_{i j k}^{*}=V_{i j k} \times \varepsilon V_{i j k}, \varepsilon V_{i j k} \sim T D\left(1-2 \sigma_{v} 1+2 \sigma_{v}\right)
$$

Table 6 provides the values of the relative volume error $\sigma_{v}$ by species group and species abundance.

\section{Uncertainty in sub-plot areas}

In the aerial image of a photo-plot, the boundaries separating sub-plot areas vary from sharp/crisp to subtle/fuzzy transitions in land use and land cover. The precision of delineations varies accordingly, and is, in addition, influenced by the interpreter, image properties, and topography (Ståhl 1992; Næsset 1997, 1998; Strand et al. 2002; Ihse 2007). In a single photo-

Table 5. Standard deviation $\sigma_{\varepsilon H T}$ in normally distributed mean-zero errors of average height of leading species.

\begin{tabular}{llll}
\hline $\begin{array}{l}\text { Maturity Class } \\
\text { (MAT) }\end{array}$ & $\begin{array}{l}\text { Stand Complexity } \\
\text { (LAYER) }\end{array}$ & $\begin{array}{l}\text { Species group } \\
\text { (TAXA) }\end{array}$ & $\begin{array}{l}\sigma_{\varepsilon H T} \\
(\mathbf{m})\end{array}$ \\
\hline \multirow{2}{*}{ Regeneration, Sapling, Young } & Single layer & Softwoods (S) & 0.5 \\
& $\begin{array}{l}\text { Single layer } \\
\text { Multiple layers }\end{array}$ & $\begin{array}{l}\text { Hardwoods (H) } \\
\text { S and H }\end{array}$ & 0.6 \\
& & & 0.9 \\
Immature/ Mature/Over-mature & Single layer & Softwoods (S) & 0.7 \\
& Single layer & Hardwoods (H) & 0.8 \\
& Multiple layers & S and H & 1.2 \\
\hline
\end{tabular}


Table 6. Relative uncertainty in volume estimates by species group and abundance. is expressed in percent of the volume assigned to a species. Species by abundance class are in Table 2.

\begin{tabular}{lcccc}
\hline & \multicolumn{4}{c}{ Abundance } \\
\cline { 2 - 5 } Species group & High & Average & Low & Very low \\
\hline Softwoods & 15 & 17 & 19 & 21 \\
Hardwoods & 17 & 20 & 23 & 26 \\
\hline
\end{tabular}

plot, the precision of the recorded sub-plot areas may, therefore, vary a great deal depending on a large number of factors specific to the interpreter and the sub-plot delineation process. Across photo-plots, the area precision will also vary due to interpreters, variation in image properties, land cover, land use, and topography.

To simplify matters, and because our goal is to quantify the impact of uncertainty in interpreted attributes on NFI estimates of presumed sampling error (i.e., precision), we adopted a single model for the uncertainty in area values recorded for sub-plot areas. First we assumed that the total area of a photo-plot ( $400 \mathrm{ha}$ ) is known without error. Thus, all errors related to the delineation sum to zero within a photoplot. It was assumed, that sub-plot boundaries, between adjoining treed areas, can be located, on average, to within $2 / 3$ of a millimetre from the "true" boundary on the 1:12500 (1:15 000) aerial photographs used in NB (NS) (Magnussen 1996). In NB and NS, with an average treed sub-plot area of approximately 6 ha, the relative area error-given the aforementioned assumptions and also assuming an irregular outline of sub-plot areas-would be approximately 3\% (Magnussen 1996). To reach this target for the expected average relative area error, the areas $\left(\alpha^{*}\right)$ of stands $\left(j=1, \ldots, n_{i}\right)$ in photo-plot $i$ were determined by a random draw from a multinomial distribution $(\mathrm{MN})$ :

$$
\text { [3] } \quad \mathrm{a}^{*}{ }_{i} \approx M N\left(8 \times 104, \varphi_{i}\right) / 200
$$

where $\varphi_{i}$ is the vector of sub-plot area proportions in the $i$ th photo-plot, i.e., the recorded areas $a_{i j}$ divided by the total area of a photo-plot (400 ha), and $\mathrm{a}^{*}{ }_{i}$ is the vector of $n_{i}$ random areas drawn from the multinomial distribution in eq. 3 . The multinomial parameters in eq. 3 were determined by trial and error. When implemented, the average relative error of a recorded area value was $2.9 \%$.

\section{Results and Discussion}

Results of the Monte Carlo simulations of the uncertainty in photo-interpreted attribute values are in Table 7. The effect of uncertainty in interpreted attributes is the expected increase in the estimate of precision (presumed sampling error) (Fuller 1987, Gertner 1991, Lesser and Kalsbeek 1999, Canavan and Hann 2004). The increase depends not only on the "intrinsic" uncertainty associated with interpretation but also on the number and size of sub-plot areas in each photo-plot. Since photo-interpretation is done on a per sub-plot area basis, and since the error in one area specific attribute value can be assumed independent from the error committed in another sub-plot area, it follows that the increase in the among-plot variance of photo-plot averages diminishes as the number of sub-plot areas contributing to the attribute goes up (Särndal et al. 1992: 601). This trend is modified by the uncertainty in sub-plot areas, which, on a relative scale, tend to be larger for smaller areas than for larger ones (Prisley et al. 1989, Magnussen 1996, Næsset 1999). In the studied set of photo-plots, the average size of a sub-plot area was 5.4 ha (median 3.6 ha, with $95 \%$ between 0.1 ha and 17.2 ha). Treed areas were, on average, larger (mean 8.0 ha, median 6.4 ha, with 95\% between 2.7 ha and 19.0 ha). A photo-plot had an average of 56 treed sub-plot areas (median 51, with a 95\% interval from 6 to 119$)$.

When examined against this background, it is perhaps not surprising to see that the estimated relative precision in 27 of the 35 attributes (77\%) listed in Table 7 increased by 0.2 percentage points or less after accounting for interpreter uncertainty. Precision estimated with and without simulated errors for attributes like forest area, stem volume, tree height, and crown closure, were practically identical. The average inflation of 0.2 percentage points is hardly a matter of concern and would barely change the statistical power of a hypothesis test (Foster 2001). A modest inflation of approximately 0.3 percentage points was seen in mature area, age of broad-leaved forest, and broad-leaved volume (Table 7). The highest inflation (greater than 0.3 percentage points, or larger than $10 \%$ in relative terms) was seen in five attributes: broadleaved area, mature area, percent broad-leaved forest, percent mixedwood forest, and percent mature forest. For the area, volume, height, and crown closure attributes, it is the uncertainty in the classes of maturity and forest type that exerts the main influence on the outcome, rather than the uncertainty in the attribute itself. The attributes most sensitive to the uncertainty of photo-interpretation are the proportions of forest types and maturity class (Table 7).

Most of the increases in the estimates of precision in Table 7 may appear trivial. Yet a large increase, as seen in some cases, will increase the rate of failure to reject a null hypothesis when it is actually false (Type II error). For example, an estimate of change that would be significant in the absence of data uncertainty may pass as "non-significant" due to the noisy nature of the data.

The size of a photo-plot $\left(4 \mathrm{~km}^{2}\right)$ in Canada's National Forest Inventory (NFI) was a decisive factor behind the modest increases in NB and NS estimates of precision due to uncertainty in photo-interpreted data. At the scale of a sub-plot area, the uncertainty in interpreted attributes can be quite large (Næsset 1991b, Ståhl 1992, Magnussen 1997a, Eid and Næsset 1998, Strand et al. 2002, Roméo and Lowell 2003). However, when the attribute errors-as in NB and NS-are averaged over an average of 56 treed sub-plot areas (range $0-150$ ), the impact of the uncertainty at the level of a photoplot is sharply reduced. This result hinges on an unverified assumption of no bias, and on independent (across sub-plot areas) errors of interpretation. Unfortunately, we still lack comprehensive studies to elucidate how reasonable these assumptions are. Without the uncertainty in photo-interpreted data a smaller photo-plot would have been more efficient (Magnussen et al. 1998). Other parts of Canada's forested landscapes have larger forest stands, hence the effect of averaging errors across sub-plot areas in a photo-plot will likely be less pronounced. 
Table 7. Monte Carlo based estimates of relative precision (presumed sampling error) (s.e. \%) in photo-interpreted inventory attributes (X). Estimates are obtained under: i) an assumption of no uncertainty in recorded attribute values $[\hat{s e}(\bar{X}) \%]$, and ii] simulated uncertainty as per details in the text $\left[\hat{s e}\left(\bar{X}^{\star}\right) \%\right]$. All table entries are rounded to the nearest $0.1 \%$. Abbreviations: TB = Hardwood forest, $T C=$ Softwood forest, $T M=$ Mixed-wood forest, $I M=$ Immature forest, $M=$ Mature forest, $C C=$ Crown closure.

\begin{tabular}{|c|c|c|c|c|c|c|c|}
\hline Attribute & $\hat{s e}(\bar{X}) \%$ & $\hat{s e}\left(\bar{X}^{\star}\right) \%$ & $\frac{\hat{s e}\left(\bar{X}^{\star}\right)}{\hat{s e}(\bar{X})}$ & Attribute & $\hat{s e}(\bar{X}) \%$ & $\hat{\operatorname{se}}\left(\bar{X}^{\star}\right) \%$ & $\frac{\hat{s e}\left(\bar{X}^{\star}\right)}{\hat{s e}(\bar{X})}$ \\
\hline Forest area & 1.88 & 1.88 & 1.00 & Stem volume & 1.93 & 1.92 & 1.00 \\
\hline $\mathrm{TB}$ area & 5.09 & 5.76 & 1.13 & TB volume & 2.99 & 3.28 & 1.09 \\
\hline $\mathrm{TC}$ area & 2.99 & 3.24 & 1.09 & TC volume & 2.50 & 2.59 & 1.03 \\
\hline M area & 2.53 & 3.46 & 1.36 & M volume & 2.04 & 2.18 & 1.07 \\
\hline IM area & 2.80 & 2.88 & 1.03 & IM volume & 2.31 & 2.33 & 1.01 \\
\hline $\mathrm{M}$ area & 5.28 & 5.57 & 1.06 & M volume & 1.45 & 1.43 & 1.02 \\
\hline ТВ\% & 5.10 & 6.07 & 1.19 & Tree height & 1.48 & 1.48 & 1.00 \\
\hline TC\% & 2.67 & 2.90 & 1.09 & TB height & 2.51 & 2.71 & 1.08 \\
\hline TM\% & 1.83 & 3.16 & 1.32 & TC height & 1.82 & 1.90 & 1.04 \\
\hline IM\% & 2.27 & 2.40 & 1.06 & TM height & 1.61 & 1.75 & 1.09 \\
\hline M\% & 4.75 & 5.35 & 1.13 & IM height & 1.56 & 1.57 & 1.01 \\
\hline Forest age & 1.72 & 1.72 & 1.00 & M height & 1.04 & 1.06 & 1.03 \\
\hline IM age & 1.68 & 1.71 & 1.02 & $\mathrm{CC}$ & 1.24 & 1.26 & 1.02 \\
\hline$M$ age & 1.20 & 1.25 & 1.04 & TB CC & 1.24 & 1.27 & 1.02 \\
\hline TB age & 3.12 & 3.40 & 1.09 & TC CC & 1.62 & 1.70 & 1.05 \\
\hline TC age & 2.18 & 2.28 & 1.04 & TM CC & 1.18 & 1.22 & 1.03 \\
\hline \multirow[t]{2}{*}{ TM age } & 1.87 & 2.04 & 1.09 & IM CC & 1.34 & 1.35 & 1.01 \\
\hline & & & & M CC & 1.01 & 1.07 & 1.07 \\
\hline
\end{tabular}

In the NFI photo-plot design, the impact of uncertainty in photo-interpreted data on estimates of precision in per-unitarea attribute values (volume per ha, for example) is a function of the uncertainty in the attribute and in the estimated sub-plot area (Hees 2002). Application of the delta technique (Kotz and Johnson 1988, Oehlert 1992) for estimating the variance of a ratio, when both the numerator and denominator are subject to errors, shows that certain combinations of relative errors can generate an apparent decrease in an estimate of precision.

Our study was limited to two provinces in eastern Canada. It will not be possible to extend the results to other provinces or territories without some modifications. The species composition and complexity of forests vary considerably across the country, and so will the level of uncertainty associated with the interpretation of a given attribute. Further variation comes from differences in the resolution and quality of aerial photographs used, in the skills of interpreters (Næsset 1991a, Ståhl 1992, Congalton and Mead 1999), and ability to exploit advantages of soft-copy technologies. Furthermore, as already discussed, the number and size distribution of sub-plot areas also vary from region to region.

Our results illustrated and confirmed that the quality of photo-interpretation is an issue that deserves careful consideration, especially for cross-classified attributes (for example, the mean age of a forest type). Choosing an optimal image resolution, optimal image properties (Fent et al. 1995, Hall and Fent 1996, Ihse 2007), ongoing extensive training of interpreters (Strand et al. 2002), and audits, are important parameters for controlling the level of uncertainty. Skilled use of soft-copy technology will provide not only more consistent results, but also affords measurements of some stand attributes. Harnessing advances in airborne laser scanning, as cur- rently done in Alberta, offers another avenue for calibration of interpreted values (Wulder et al. 2008). Forest inventories that rely on photo-interpretation usually arrange for an independent audit of the quality and consistency of the interpretation, typically through an independent re-interpretation of a selected set of stands (polygons). Although this type of audit provides an assessment of whether the inventory was done according to specifications and to acceptable levels of precision, it does not provide a quantification of the uncertainty.

A quantification of uncertainty will be expensive and therefore less likely to be done. An interpretation of, say, 100 forest stands per inventory by three different interpreters, followed by a field campaign with a $30 \mathrm{~m} \times 30 \mathrm{~m}$ network of small, fixed-area plots in each interpreted stand, would provide valuable quantitative information about the level and structure of uncertainty in extracted attributes. A reduction in the uncertainty of species identification, species proportions and species age, should be a priority (Holmgren $e t$ al. 2008) inasmuch as this non-trivial uncertainty propagates to a large number of per unit area estimates. Continued progress towards semi- and fully automated image processing procedures suggests improvements in future photo-based inventories (Fournier et al. 1995, Gougeon and Leckie 2003).

Any uncertainty (error) in natural resource survey data should, in principle, explicitly recognize this uncertainty in associated estimators of precision (Gertner and Köhl 1992). For Canada's National Forest Inventory this would translate into a considerable extra effort towards time-consuming Monte Carlo simulations, akin to those done in this study. A more likely and pragmatic alternative is to inform users of the NFI data that estimates of precision (published as sampling error) already include a component due to measurement errors. 


\section{Acknowledgements}

We are grateful to Mike McDonald and Dale Wilson (Forest Management Branch, New Brunswick Department of Natural Resources), and Peter Townsend RPF, Aaron Sutherland, Ken Newcombe, and Kim O'Donnell (Nova Scotia Department of Natural Resources, Renewable Resources Branch, Forestry Division, Forest Inventory Section) for their kind help and time with quantifying the uncertainty in photo-interpretation of forest resource attributes. Dale Wilson, Peter Townsend, Graham Stinson, and Mark Gillis provided valuable comments to an earlier draft of this paper.

\section{References}

Avery, T.E. and H.E. Burkhart. 1983. Forest Measurements. McGraw-Hill, New York.

Canavan, S.J. and D.W. Hann. 2004. The two-stage method for measurement error characterization. For. Sci. 50 (6): 743-756. Carroll, R.J., D. Ruppert and L.A. Stefanski. 1995. Measurement error in nonlinear models. Chapman \& Hall, London. Cochran, W.G. 1977. Sampling techniques. Wiley, New York.

Congalton, R.G. 2001. Precision assessment and validation of remotely sensed and other spatial information. Int. J. Wildl. Fire 10(3-4): 321-328.

Congalton, R.G. and R.A. Mead. 1999. A quantitative method to test for consistency and correctness in photointerpretation. Photogr. Eng. Rem. Sens. 49(1): 69-74.

Cots-Folch, R., M.J. Aitkenhead and J.A. Martínez-Casasnovas. 2007. Mapping land cover from detailed aerial photography data using textural and neural network analysis. Int. J. Rem. Sens. 28(7): 1625-1642.

Cox, T.F. 1976. The robust estimation of the density of a forest stand using a new conditioned distance method. Biometrika 63: 493-499. Duvemo, K. and T. Lämås. 2006. The influence of forest data quality on planning processes in forestry. Scand. J. For. Res. 21(4): 327-339.

Eid, T. and E. Næsset. 1998. Determination of stand volume in practical forest inventories based on field measurements and photointerpretation: The Norwegian experience. Scand. J. For. Res. 13: 246-254.

Fent, L., R.J. Hall and R.K. Nesby. 1995. Aerial films for forest inventory: Optimizing film parameters. Photogr. Eng. Rem. Sens. 61(3): 281-289.

Foster, J.R. 2001. Statistical power in forest monitoring. For. Ecol. Manage. 151: 211-222.

Fournier, R.M., G. Edwards and N.R. Eldridge. 1995. A catalogue of potential spatial discriminators for high spatial resolution digital images of individual crowns. Can. J. Rem. Sens. 21: 285-298. Frayer, W.E. and G.M. Furnival. 1999. Forest survey sampling designs a history. J. For. 97(12): 4-10.

Fuller, W.A. 1987. Measurement Error Models. Wiley, New York. Fuller, W.A. and E.G. Battese. 1974. Estimation of linear models with crossed-error structure. J. Econometrics 2: 67-78.

Gertner, G.Z. 1991. The sensitivity of measurement error in stand volume estimation. Can. J. For. Res. 20 (6): 800-804.

Gertner, G.Z. and M. Köhl. 1992. An assessment of some nonsampling errors in a national survey using an error budget. For. Sci. 38: 525-538.

Gillis, M.D. and D.G. Leckie. 1993. Forest inventory mapping procedures across Canada. Petawawa National Forestry Institute, Forestry Canada, Chalk River, ON. Information Report. PI-X-114. $79 \mathrm{p}$.

Gillis, M.D., A.Y. Omule and T. Brierley. 2005. Monitoring Canada's forests: The National Forest Inventory. For. Chron. 81(2): 214-221.
Gougeon, F.A. and D.G. Leckie. 2003. Forest information extraction from high spatial resolution images using an individual tree crown approach. Natural resources Canada, Canadian Forest Service, Victoria BC. Information Report BC-X-396. 25 p.

Haara, A. and P. Leskinen. 2009. The assessment of the uncertainty of updated stand-level inventory data. Silv. Fenn. 43(1): 87-112.

Hall, R.J. and L. Fent. 1991. Relating forestry interpreter preference to sensitometric parameters of black and white and normal color aerial films. ISPRS Journal of Photogr. Rem. Sens. 46(6): 328-345.

Hall, R.J. and L. Fent. 1996. Influence of aerial film spectral sensitivity and texture on interpreting images of forest species composition. Can. J. Rem. Sens. 22(4): 350-359.

Hees, W.W.S. 2002. A comparison of two estimates of standard error for a ratio-of-means estimator for a mapped-plot sample design in southeast Alaska. Portland, OR. PNW-532. 9 p.

Holmgren, J., A. Persson and U. Söderman. 2008. Species identification of individual trees by combining high resolution LIDAR data with multi-spectral images. Int. J.Rem. Sens. 29(5): 1537-1552.

Ihse, M. 2007. Colour infrared aerial photography as a tool for vegetation mapping and change detection in environmental studies of Nordic ecosystems: A review. Norsk Geografisk Tidsskrift 61(4): 170-191.

Johnson, N.L., S. Kotz and N. Balakrishnan. 1995. Continuous univariate distributions. Vol. 2. 2nd Ed. Wiley, New York.

Köhl, M. and M. Keller. 1999. Aerial photo-interpretation using analytical plotters for Swiss Land Forest Inventory. Mitt. Eidgenöss. Forsch. Anst. Wald Schnee Landsch. 12(6): 13-19.

Korpela, I. 2004. Individual tree measurements by means of digital aerial photogrammetry. Silva Fennica Monographs 3 2004.93 p.

Kotz, S. and N. L. Johnson. 1988. Taylor-series linearization. In S. Kotz and N.L. Johnson (eds.). Encyclopedia of Statistical Sciences. pp. 646-647. John Wiley, New York.

Leckie, D.G. and M.D. Gillis. 1995. Forest inventory in Canada with emphasis on map production. For. Chron. 71(1): 74-78.

Lesser, V.M. and W.D. Kalsbeek. 1999. Nonsampling errors in environmental surveys. J. Agric. Biol. Environ. Stat. 4(4): 473-488.

Levy, P.S. and S. Lemeshow. 1991. Sampling of populations: Methods and applications. Wiley, New York.

Loetsch, F., F. Zöhrer and K.E. Haller. 1973. Forest Inventory. BLVVerlagsgesellschaft. Munich.

Magnussen, S. 1996. A coordinate-free area variance estimator for forest stands with a fuzzy outline. For. Sci. 42(1): 76-85.

Magnussen, S. 1997a. Calibrating photo-interpreted forest cover types and relative species compositions to their ground expectations. Can. J. For. Res. 27: 491-500.

Magnussen, S. 1997b. A method for enhancing tree species proportions from aerial photos. For. Chron. 73: 479-487.

Magnussen, S. 1998. Tree height tarifs and volume estimation errors in New Brunswick. N. J. Appl. For. 15(1): 7-13.

Magnussen, S., P. Boudewyn and M.D. Gillis. 1998. Towards a plot size for Canada's national forest inventory. In M. Hansen and T. Burk (eds.). Integrated tools for natural resources inventories in the 21st century, Proceedings: IUFRO Conference. August 16-20, 1998, Boise, ID. pp. 116-128. USDA Forest Service, St. Paul, MN, General Technical Report NC-212.

Magnusson, M., J.E.S. Fransson and H. Olsson. 2007. Aerial photo-interpretation using Z/I DMC images for estimation of forest variables. Scand. J. For. Res. 22(3): 254-266.

Mäkinen, A., A. Kangas and L. Mehtätalo. 2010. Correlations, distributions, and trends in forest inventory errors and their effects on forest planning. Can. J. For. Res. 40(7): 1386-1396.

Morgan, J.L., S.E. Gergel and N.C. Coops. 2010. Aerial photography: A rapidly evolving tool for ecological management. BioSci. 60(1): 47-59.

Næsset, E. 1991a. Precision of stand volume estimation by means of strata mean values. Medd. Norsk Inst. Skogforsk. 44: 24 p. 
Næsset, E. 1991b. Prediction of mean diameter, tariff number and gross value in stands by means of aerial photographs. Report from the Nor. For. Res. Inst. 19(3): 19 p.

Næsset, E. 1992. Interpretation of tree species mixture on infrared and panchromatic aerial photographs. Medd. Norsk Inst. Skogfosk. 45: $22 \mathrm{p}$.

Næsset, E. 1995. Determination of mean diameter by basal area in stands of Picea abies and Pinus sylvestris in Southeastern Norway by means of aerial photographs. Scand. J. For. Res. 10: 296-304.

Næsset, E. 1997. The precision of estimated stand area delineated by aerial photointerpretation. Medd. Norsk Inst. Skogforsk 48: 275-285.

Næsset, E. 1998. Positional precision of boundaries between clearcuts and mature forest stands delineated by means of aerial photointerpretation. Can. J. For. Res. 28: 368-374.

Næsset, E. 1999. Assessing the effect of erroneous placement of forest stand boundaries on the estimated area of individual stands. Scand. J. For. Res. 14(2): 175-181.

O’Cuilinn, M. 1994. Wisconsin aerial photography project presents special challenges to contractors. Earth Obser. Mag. 3(9): 44-46. Oehlert, G.W. 1992. A Note on the Delta Method. Am. Stat. 46(1): 27-29.

Prisley, S.P., T.G. Gregoire and J.L. Smith. 1989. The mean and variance of area estimates computed in an Arc-node geographic information system. Photogr. Eng. Rem. Sens. 55: 1601-1612.

Roméo, F.T. and K. Lowell. 2003. Relationships between groundbased forest data and a multiple-interpretation-based certainty map. Env. Model. Softw 18(7): 619-626.
Rubin, D.B. 1987. Multiple imputation for nonresponse in surveys. Wiley, New York.

Särndal, C.E., B. Swensson and J. Wretman. 1992. Model assisted survey sampling. Springer, New York.

Shedha, M.D. and T. Natarajan. 1978. Role of aerial photographs and landsat imagery in forest resources surveys. J Ind. Soc. PhotoInterpret. 6(1): 1-7.

Spencer, R.D. 1998. Small format aerial photography: Methods and achievements in Australian forestry. Austral. For. 61(4): 267-274.

Spencer, R.D. and R.L. Czaplewski. 1997. National forest inventory in the USA: An outline of the procedure. Austral. For. 60(1): 56-66. Ståhl, G. 1992. A study on the quality of compartmentwise forest data acquired by subjective inventory methods. S. U. o. A. Sciences. Umeå, SE. 24. 128 p.

Ståhl, G. et al. 2011. National Inventory of Landscapes in Sweden (NILS)-scope, design, and experiences from establishing a multiscale biodiversity monitoring system. Env. Monit. Assess. 173(1-4): 579-595.

Strand, G.H., W. Dramstad and G. Engan. 2002. The effect of field experience on the precision of identifying land cover types in aerial photographs. International Journal of Appl. Earth Obs. Geoinf. 4(2): 137-146.

Wulder, M.A., C.W. Bater, N.C. Coops, T. Milker and J.C. White. 2008. The role of LiDAR in sustainable forest management. For. Chron. 84: 807-826. 